\section{Impact of a single educational session on oral hygiene prac- tices among children of a primary school of Meerut, India}

\author{
Pawan Parashar, ${ }^{1}$ Sartaj Ahmad, 2 \\ Amir Maroof Khan, ${ }^{3}$ Rupesh Tiwari ${ }^{1}$ \\ 'Department of Community Medicine, \\ Subharti Medical College Meerut, Meerut; \\ 2School of Community Medicine, Swami \\ Vivekanand Subharti University, Meerut; \\ ${ }^{3}$ Department of Community Medicine, \\ University College of Medical Sciences, \\ New Delhi, India
}

\section{Abstract}

Oral health promotion through schools is recommended by the World Health Organization (WHO) for improving knowledge, attitude, and behavior related to oral health and for prevention and control of dental diseases among school children. In low resource settings, it is important to develop evidence for health education methods in oral health behavioral practices. The objectives of this study were to assess both the baseline awareness and practices regarding oral hygiene and the impact of a single education session on the change in oral health behavior. A school based, cross-sectional study on 112 primary school children was conducted after obtaining the consent of the school authorities and parents. A pretested, structured proforma was used for baseline awareness and behavior regarding oral health. A 30 min educational session was imparted and after 1 month, and the oral health practices were reassessed to find out the impact of the education session. Baseline survey revealed the following findings. Self-reported dental problems were found in $48.22 \%$ of the children in the last 6 months. When asked about the risk factors for dental problems, $28.57 \%$ mentioned eating sweets followed by improper brushing, whereas $40.17 \%$ were not aware about any risk factor for dental problems. It was found that $28.57 \%$ of the children did not brush their teeth regularly, whereas $35.71 \%$ used a toothbrush for brushing their teeth. After the intervention, it was observed that there was a significant improvement in the proportion of children using a toothbrush for cleaning their teeth and of those who rinsed their mouth after meals. In conclusion, even a single education session was found to be effective in bringing about a change in the oral health behavior of primary school children.

\section{Introduction}

Oral health is an integral part of the general health and well-being of an individual. Oral health promotion through schools is recommended by the World Health Organization (WHO) for improving knowledge, attitude, and behavior related to oral health and for prevention and control of dental diseases among school children. ${ }^{1}$ Children tend to be more vulnerable to dental diseases due to social, economic and demographic factors like lack of awareness and transportation, limited access to professional dental care, lack of perceived need for dental care. ${ }^{2}$ Schools are a suitable place for imparting knowledge to the school children and school children also are receptive to the information given to them. School children can act as health change agents in the community. ${ }^{3}$ The National Education Policy of India also encourages linkages between education and health. Studies conducted in India have focused mostly on adolescents ${ }^{4}$ or they have compared different methods of health education regarding dental hygiene practices. ${ }^{5}$ There are hardly any studies among primary school students where the impact of just one education session for oral hygiene practices have been seen. ${ }^{6}$ There exists a need to change the unhealthy practices regarding oral hygiene into healthy ones, and targeting school children is an important and effective strategy. Hence, this study was designed with the following objectives: i) to assess the baseline awareness and practices regarding oral hygiene among children attending a primary school in Meerut; ii) to assess the impact of a single educational session on the practices regarding oral hygiene among children attending a primary school in Meerut.

\section{Materials and Methods}

The study was a cross-sectional, schoolbased interventional study. All children $(n=112)$ aged 5-13 years who attended Ishwarchandra Vidhyasagar Subharti Primary school were included in the study. These children come from a peri-urban slum of Meerut district of Uttar Pradesh, India.

A written permission was obtained from the school authorities before the commencement of the study. Informed consent was obtained from the parents of the children studied and verbal assent was taken from the children themselves. The knowledge, attitude and practices regarding oral hygiene of the children was assessed by using a pre-designed and a pre-tested questionnaire. Using a mouth mirror and explorer, examination of oral cavity of the children was done by dental screening in broad day light, facing away from sunlight to
Correspondence: Amir M. Khan, Department of Community Medicine, University College Medical Sciences, Dilshad Garden, 110095 New Delhi, India.

Tel. +91.011.22582106 - Fax: +91.011.22582105

E-mail: khanamirmaroof@yahoo.com

Key words: health education, school children, oral health, dental hygiene.

Contributions: PP and SA conceived the idea of the manuscript and developed interview tools and data collection; PP, AMK and SA prepared the manuscript; RT analyzed data.

Conflict of interests: the authors declare no potential conflict of interests.

Received for publication: 27 June 2013.

Revision received: 16 July 2013.

Accepted for publication: 28 July 2013.

This work is licensed under a Creative Commons Attribution 3.0 License (by-nc 3.0).

(C) Copyright P. Parashar et al., 2013

Licensee PAGEPress, Italy

Healthcare in Low-resource Settings 2013; 1:e24 doi:10.4081/hls.2013.e24

detect clinically evident caries lesions and oral hygiene status. The examination of oral cavity of the children was conducted by a dentist. Those who were having problems related to teeth were given treatment free of cost.

An educational session of 30 min duration, comprising the lecture and demonstrations in local language (Hindi), was carried out by the first and second author of the study in groups of 20-30 children. Pictorial charts depicting the common oral health problems and techniques of maintaining a healthy oral hygiene was used. A model of an oral cavity was used to further enhance its understanding in three dimensions. Finally a demonstration was conducted for proper brushing of teeth and a toothbrush was distributed free of cost to each student. Re-assessment for the oral hygiene practices was done among the same group of children after a period of 1 month.

Data was entered in MS Excel spreadsheet and analysed using EPI Info for Windows. Z test for proportions was used to test the difference in the proportions and $\mathrm{P}<0.05$ was considered as statistically significant.

\section{Results}

A total of 112 children aged 5-13 years of age were examined twice, once before the intervention and then after one month of intervention. Of these, 72 (64.29\%) were males and 40 (35.71\%) were females. 


\section{Pre-intervention findings}

Self reported dental problems were found in $54(48.22 \%)$ of the children in the last six months. Out of these, 19 (35.19\%) children had consulted the dental surgeon, 12 (22.22\%) had consulted any doctor for consultation and 23 (42.59\%) had used home based measures when they experienced any dental problem.

The most common response (33.93\%) for common oral health problems was mentioned as tooth decay. Other oral health problems reported were bad smell (15.17\%), cracked teeth (10.71\%), toothache (7.14\%) and gum diseases (4.46\%), whereas $17.85 \%$ were not able to report any oral health problem.

When asked about the risk factors for dental problems, majority (28.57\%) mentioned eating sweets followed by improper brushing $(17.85 \%)$. Not rinsing the mouth was mentioned as a risk factor by only $8.73 \%$, and $40.17 \%$ were not aware about any risk factor for dental problems.

Regarding the practices for maintaining oral hygiene, it was found that majority (35.71\%) brushed their teeth with a toothbrush, whereas $22.32 \%$ used their finger for cleaning the teeth, $8.93 \%$ used other abrasive materials like coal etc., and 4.46\% used neem's or some other plant's twig for cleaning their teeth, whereas $28.57 \%$ did not bush their teeth regularly and did not have any fixed method of cleaning their teeth.

\section{Post-intervention findings}

There was a significant improvement -i.e. from $35.71 \%$ in the pre-intervention phase to $58.93 \%$ in the post-intervention phase - in the proportion of children using a toothbrush for cleaning their teeth $(\mathrm{P}<0.001)$. A significant increase in proportion of children who rinsed their mouth after meals also increased from 8.04 to $24.11 \%(\mathrm{P}=0.001)$ after the intervention. The proportion of children using other things to clean their brush other than a tooth brush, like charcoal, plant's twigs etc. declined significantly post intervention: from 35.71 to $23.21 \%(\mathrm{P}=0.04)$.

\section{Discussion}

In recent years, there is a growing emphasis on oral health and it is important to focus on the vulnerable groups of the society, especially children belonging to a lower socioeconomic status.

Nearly half (52.8\%) of the respondents in a study by Mehta and Kaur ${ }^{7}$ have reported as having some dental problem in the last 12 months, which was nearly similar to the findings of the present study. Another study by David et al. ${ }^{8}$ from Kerala has observed that $23 \%$ of the school children, had self reported dental problems, which was lower than that in the present study. Ayele et $a l .{ }^{9}$ have reported from a community based study in Ethiopia, that $67.3 \%$ of parents of the children having any dental problem were taken to any formal health care provider. This was higher than that reported in the present study.

In a study by Diwan et al. ${ }^{10}$ from Meerut, 53.4 and $60.1 \%$ of the children studied suffered from gingivitis and dental caries, respectively, which was higher than in the present study, since in Diwan and colleagues' study the diagnosis was made by a physician, whereas in the present study self reported problems were recorded.

Joshi et al. ${ }^{11}$ has reported from a village in Tamil Nadu, that $61 \%$ of children between $6-12$ years knew about tooth decay. This was higher than that reported in the present study.

A study by Sreebny using data on sugar supplied in various countries and data on caries prevalence obtained from WHO for 6-year-old children in 23 nations and 12-year olds in 47 nations, showed that the availability of $<50 \mathrm{~g}$ of sugar per person per day in a country was always associated with decayed, missing, filled teeth (DMFT) scores $<3 .{ }^{12}$ Similar findings were reported by Winter and Rule ${ }^{13}$ and Shetty and Tandon. ${ }^{14}$

In the present study, $35.71 \%$ children were using tooth brush and $22.32 \%$ of children were using fingers to clean their teeth. Using a brush for cleaning the teeth has been reported as 62.96 and $71.4 \%$ among school going children by Punitha and Sriprakasam ${ }^{15}$ and Mehta and Kaur, ${ }^{7}$ respectively. These figures are higher than that reported in the present study. It may be due to the migrant labor population studied in the present study which cannot afford or do not give priority to oral hygiene due to lack of awareness. In a study by Mehta and Kaur, 17.3 and $4.1 \%$ of the children studied reported use of neem twigs and finger, respectively, for cleaning their teeth. ${ }^{7}$ In the present study, the proportion of children using neem twigs was lower but children using their fingers for cleaning their teeth was higher than in this study. Another study from South India has also reported use of charcoal for brushing teeth among school going children. ${ }^{16}$

However, it should be noticed that children not using any fixed modality for cleaning their teeth was high (28.57\%) in the present study. This highlights that these children are not seriously regarding oral hygiene.

Studies have shown that health education can improve the knowledge and to some extent the behavior regarding healthy oral hygiene practices. ${ }^{17}$ Chaudhary et al. from Delhi have reported an improvement in the knowledge regarding oral health after health education. ${ }^{18}$ However, this study did not assess the change in oral health behavior in the children studied. Another study has revealed that dental health education given at 3 -week-intervals was more effective than that at 6 -week-intervals. ${ }^{19}$

As teachers already have other tasks to perform, they may not find much time to impart health education to children, which involves a considerable amount of time. Hence, it is necessary to assess the impact of short duration education sessions on their oral health related practices.

Overall, the level of oral health knowledge among the surveyed children was low. Results of this study suggest that oral health practices can be improved by even a single education session.

\section{Limitations of the study}

The study was done in a single school and its results cannot be generalized. No control group was chosen in this study, but since this was a preliminary study, further studies need to be planned with a representative sample from the population and using a control group for comparison. Another limitation was that this study did not measure the effectiveness of the intervention in the long term.

\section{Conclusions}

Inclusion of even a single education session on oral hygiene for school children can lead to a change in their behaviors and thus it can be promoted in schools even with resource poor settings. More studies need to be done to see the long term effect of such interventions.

\section{References}

1. Peterson PE. World Health Organization global policy for improvement of oral health. Int Dent J 2008;58:115-21.

2. Grewal H, Verma M. Oral health status in rural child population: promotional and interventional strategies. A GOI-WHO collaborative programme 2006-07. Available from: ftp://203.90.70.117/searoftp/ WROIND/whoindia/LinkFiles/Oral_Health _Oral_Health_Status_in_rural_child_pop ulation.pdf

3. Mwanga JR, Jensen BB, Magnussen P, Aagaard-Hansen J. School children as health change agents in Magu, Tanzania: a feasibility study. Health Promot Int 2008; 23:16-23.

4. Shenoy RP, Sequeira PS. Effectiveness of a school dental education program in improving oral health knowledge and oral hygiene practices and status of 12- to 13year-old school children. Indian J Dent Res 2010;21:253-9. Available from: http:// www.ijdr.in/text.asp?2010/21/2/253/66652 
5. Hebbal M, Ankola AV, Vadavi D, Patel K. Evaluation of knowledge and plaque scores in school children before and after health education. Dent Res J (Isfahan) 2011;8: 189-96.

6. Goel P, Sehgal M, Mittal R. Evaluating the effectiveness of school-based dental health education program among children of different socioeconomic groups. J Indian Soc Pedod Prev Dent 2005;23:131-3.

7. Mehta A, Kaur G. Oral health-related knowledge, attitude, and practices among 12-year-old school children studying in rural areas of Panchkula, India. Indian J Dent Res 2012; 23:293.

8. David J, Wang NJ, Astrom A, Kuriakos S. Dental caries and associated factors in 12 year-old schoolchildren in Thiruvananthapuram, Kerrala, India. Int J Paediatr Dent 2005;15:420-8.

9. Ayele FA, Taye BW, Ayele TA, Gelaye KA. Predictors of dental caries among children 7-14 years onld in Northwest Ethiopia: a community based cross-sectional study. BMC Oral Health 2013;13:7.

10. Diwan S, Saxena V, Bansal S, et al. Oral health: knowledge and practices in rural community. Indian $\mathrm{J}$ Community Health
2013;22:29-31. Available from: http://www. iapsmupuk.org/journal/index.php/IJCH/art icle/view/398/pdf

11. Joshi N, Rajesh R, Sunitha M. Prevalence of dental caries among school children in Kulasekharam village: A correlated prevalence survey. J Indian Soc Pedod Prev Dent 2005;23:138-40. Available from: http://www. jisppd.com/text.asp?2005/23/3/138/16887

12. Sreebny LM. Sugar availability, sugar consumption and dental caries. Community Dent Oral 1982;10:1-7.

13. Winter GB, Rule DC. The prevalence of dental caries in pre-school children aged 1 to 4 years. Brit Dent J 1971;130:434.

14. Shetty NS, Tandon S. Prevalence of dental caries as related to risk factors in school children of South Kanara. J Indian Soc Pedod Prev Dent 1988;6:30-7.

15. Punitha VC, Sriprakasam P. Oral hygiene status, knowledge, attitude and practices or oral health among rural children of Kanchipuram district. Indian J Multidisciplinary Dentistry 2011;1:115-8. Available from: http://www.ijmdent.com/ Articles/volume1-issue2/original-researchoral-hygiene.pdf

16. Mahesh KP, Joseph T, Varma RB, Jayanthi
M. Oral health status of 5 years and 12 years school going children in Chennai city. An epidemiological study. J Indian Soc Pedod Prev Dent 2005;23:17-22. Available online from: http://www.jisppd.com/ text. asp?2005/23/1/17/16021

17. Kay E, Locker D. A systematic review of the effectiveness of health promotion aimed at improving oral health. Community Dent Hlth 1998;15:132-44.

18. Chaudhary F, Khayyam KU, Siddiqui MJ, et al. Impact of teaching on dental knowledge in fifth standard of MCD primary school children of South Delhi. Journal Applied Pharm Sci 2011;1:91-3. Available from: http://www.japsonline.com/admin/php/uplo ads/179_pdf.pdf

19. Shenoy RP, Sequeira PS. Effectiveness of school dental education program in improving oral health knowledge and oral hygiene practices and status of 12-13-year old school children. Indian J Dent Res 2010;21:253-9. Available from: http://im sear.hellis.org/bitstream/123456789/139 858/1/ijdr2010v21n2p253.pdf 